
NASA/TM-2001-210604
$14 P$
AIAA-2000-3021

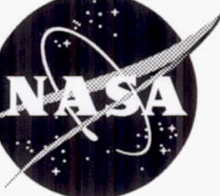
Assessment of the Free-Piston Stirling
Convertor as a Long Life Power
Convertor for Space

Jeffrey G. Schreiber

Glenn Research Center, Cleveland, Ohio 
Since its founding, NASA has been dedicated to the advancement of aeronautics and space science. The NASA Scientific and Technical Information (STI) Program Office plays a key part in helping NASA maintain this important role.

The NASA STI Program Office is operated by Langley Research Center, the Lead Center for NASA's scientific and technical information. The NASA STI Program Office provides access to the NASA STI Database, the largest collection of aeronautical and space science STI in the world. The Program Office is also NASA's institutional mechanism for disseminating the results of its research and development activities. These results are published by NASA in the NASA STI Report Series, which includes the following report types:

- $\quad$ TECHNICAL PUBLICATION. Reports of completed research or a major significant phase of research that present the results of NASA programs and include extensive data or theoretical analysis. Includes compilations of significant scientific and technical data and information deemed to be of continuing reference value. NASA's counterpart of peerreviewed formal professional papers but has less stringent limitations on manuscript length and extent of graphic presentations.

- TECHNICAL MEMORANDUM. Scientific and technical findings that are preliminary or of specialized interest, e.g., quick release reports, working papers, and bibliographies that contain minimal annotation. Does not contain extensive analysis.

- CONTRACTOR REPORT. Scientific and technical findings by NASA-sponsored contractors and grantees.
- CONFERENCE PUBLICATION. Collected papers from scientific and technical conferences, symposia, seminars, or other meetings sponsored or cosponsored by NASA.

- SPECIAL PUBLICATION. Scientific, technical, or historical information from NASA programs, projects, and missions, often concerned with subjects having substantial public interest.

- TECHNICAL TRANSLATION. Englishlanguage translations of foreign scientific and technical material pertinent to NASA's mission.

Specialized services that complement the STI Program Office's diverse offerings include creating custom thesauri, building customized data bases, organizing and publishing research results ... even providing videos.

For more information about the NASA STI Program Office, see the following:

- Access the NASA STI Program Home Page at http://www.sti.nasa.gov

- E-mail your question via the Internet to help@sti.nasa.gov

- Fax your question to the NASA Access Help Desk at 301-621-0134

- Telephone the NASA Access Help Desk at 301-621-0390

- Write to:

NASA Access Help Desk

NASA Center for AeroSpace Information 7121 Standard Drive Hanover, MD 21076 


\section{Assessment of the Free-Piston Stirling Convertor as a Long Life Power Convertor for Space}

Jeffrey G. Schreiber

Glenn Research Center, Cleveland, Ohio

Prepared for the

35th Intersociety Energy Conversion Engineering Conference Energy and Power in Transition sponsored by the American Institute of Aeronautics and Astronautics Las Vegas, Nevada, July 24-28, 2000

National Aeronautics and Space Administration

Glenn Research Center 
This report contains preliminary findings, subject to revision as analysis proceeds.

Available from

NASA Center for Aerospace Information 7121 Standard Drive

Hanover, MD 21076

Price Code: A03
National Technical Information Service 5285 Port Royal Road Springfield, VA 22100

Price Code: A03 


\title{
ASSESSMENT OF THE FREE-PISTON STIRLING CONVERTOR AS A LONG LIFE POWER CONVERTOR FOR SPACE
}

\author{
Jeffrey G. Schreiber \\ National Aeronautics and Space Administration \\ Glenn Research Center \\ Cleveland, Ohio 44135
}

\begin{abstract}
$\underline{\text { ABSTRACT }}$
There is currently a renewed interest in the use of freepiston Stirling power convertors for space power applications. More specifically, the Stirling convertor is being developed to be part of the Stirling Radioisotope Power System to supply electric power to spacecraft for NASA deep space science missions. The current development effort involves the Department of Energy, Germantown, MD, the NASA Glenn Research Center, Cleveland, $\mathrm{OH}$, and the Stirling Technology Company, Kennewick, WA. The Stirling convertor will absorb heat supplied from the decay of plutonium dioxide contained in the General Purpose Heat Source modules and convert it into electricity to power the spacecraft. For many years the "potentials" of the freepiston Stirling convertor have been publicized by it's developers. Among these "potentials" were long life and high reliability. This paper will present an overview of the critical areas that enable long life of the free-piston Stirling power convertor, and present some of the techniques that have been used when long life has been achieved.
\end{abstract}

\section{BACKGROUND}

Radioisotope power systems were first used in the Unites States space program in 1961. Radioisotope generators were used on the Transit $4 \mathrm{~A}$ and $4 \mathrm{~B}$ satellites. These power systems were called Systems for Nuclear Auxiliary Power (SNAP) ${ }^{1}$. The series of Transit satellites were designed by Johns Hopkins University and were launched into earth orbit. Each of the satellites had two double-frequency transmitters, and were used for naval navigation purposes. It is interesting to note that this system was used not only by the Navy, but was also used in commercial shipping, for charting offshore oil and mineral deposits, and also to aid land surveying programs.

Since the 1960's, radioisotope power systems have been the power system of choice for many of the interplanetary probes. There have been over 200 space science probes launched and radioisotope power systems have been used for the missions to the more distant reaches of the outer planets. This is because the intensity of the sun light is significantly reduced at greater distances from the sun, and the mass of solar powered systems grows to compensate, and often reach unacceptable limits.

Radioisotope power systems were put into earth orbit as late as 1967 on the Lincoln Experimental Satellite (LES) 8 and 9, designed and built for the Air Force by the Massachusetts Institute of Technology Lincoln Laboratory. LES 8 and 9 were used as communications satellites. Radioisotope power systems were also used in the Apollo program from 1969 through 1972, however radioisotope systems are currently only considered for use on interplanetary missions. Even for these interplanetary missions, it is required by NASA regulations that the mission office consider using an alternative, non-nuclear power source before an isotope power source can be used. ${ }^{2}$

\section{INTRODUCTION}

Under the current direction of NASA, spacecraft for space science missions have become smaller and use less electric power when compared to earlier spacecraft ${ }^{3,4}$. The most recent, and perhaps the last of the large deep space probes was Cassini, launched in October of 1997. The power system used was the Radioisotope Thermoelectric Generator (RTG), the same system design as had been previously used on the Galileo and Ulysses spacecraft. The RTGs use unicouples to convert heat to electricity, and are approximately $6 \%$ efficient. They have demonstrated extraordinary reliability in support of the 26 missions on which they have been used. The Cassini power system contained almost $33 \mathrm{~kg}$ (72 lbs) of radioactive plutonium dioxide (Pu-238) in the RTGs and 115 grams $(0.7 \mathrm{lbs})$ in the heater units. The power system will produce 628 -We at the end of the 11 year mission to Saturn. 
The Department of Energy (DOE) has legal responsibility for the development and production of nuclear and isotope systems in the United States. It is for this reason that $\mathrm{DOE}$ has responsibility for developing and supplying the isotope power systems used on NASA missions. Motivated by the high cost of $\mathrm{Pu}-238$, and in response to the environmental concerns of the public, DOE is developing a new power system for NASA deep space science missions. The new power system will be based on the high efficiency freepiston Stirling power conversion technology 5 . DOE and the NASA Glenn Research Center (GRC), Cleveland, $\mathrm{OH}$ are collaborating with the Stirling Technology Company (STC) of Kennewick, WA in the development of a free-piston Stirling convertor for this application. The Stirling power system has recently been selected for use on the Europa Orbiter and Solar Probe missions. The efficiency of the Stirling power system will be over $20 \%$, which will reduce the radioisotope inventory by a factor of 3 or more compared to the RTGs.

The free-piston Stirling convertor being developed for this system is the $55-$ We Technology Demonstration Convertor (TDC), as shown in figure 1. This development effort has been performed by the STC under contract to $\mathrm{DOE}^{6,7}$. The TDC successfully achieved the power and efficiency goals set by DOE, and in a dynamically balanced configuration was able to reach vibration levels acceptable for the aforementioned missions. All of the missions for which this power system is being considered require a highly reliable power system, and all of the missions envisioned are multi-year in length.

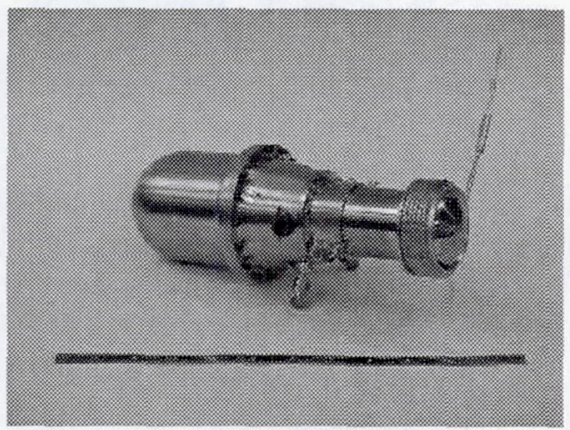

Figure 1. - The 55-We Technology

Demonstration Convertor (TDC).

\section{THE OP/SP MISSIONS}

The missions intended to be first to use of the new power system, Europa Orbiter and Solar Probe, are currently scheduled for launch in 2006 and 2007 respectively. The missions are part of the Outer Planets/Solar Probe (OP/SP) mission set, managed by the Jet Propulsion Laboratory (JPL) of Pasadena, CA. For these missions, JPL uses a fault tolerance specification rather than a reliability specification, however in either case, this generally translates into a requirement for long life and high reliability from power system.

The first of the two missions is to Europa, one of the moons of Jupiter, where the spacecraft will be placed into orbit. As currently planned, the mission will last six years. Since a power system fueled by a radioisotope heat source starts to operate at the time of fueling, the total time that the power system will need to operate is approximately seven years or more. The first challenging aspect of the mission for the power system is the launch. During this time the power system must be operating and will be subject to high levels of random vibration. It is critical that the Stirling convertor, with it's moving parts, retain the quality and structural integrity that allows it to have long life and high reliability on the ground.

Another demanding aspect of this mission is the extremely high radiation dosage that will be encountered once the spacecraft enters the Jovian environment. Free-piston Stirling convertors operated in the laboratory typically rely on a number of organics such as exopies, teflon and/or teflon derivatives, and securing agents for threaded fasteners. The organics commonly used in the laboratory convertors are susceptible to radiation damage, and therefore, all of the organics typically used for terrestrial applications must be replaced with substitutes that can tolerate the radiation.

The second Stirling powered mission is Solar Probe. This is intended to last approximately the same length of time as Europa Orbiter. As was the case in the Europa Orbiter mission, the power system is assumed to operate for one year prior to launch. Although the Solar Probe mission does not have the same radiation requirement that exists in the Europa Orbiter mission, the random vibration launch environment will be essentially the same.

\section{THE SRPS}

Spacecraft have been put into earth orbit and beyond since the 1957 launch of Sputnik. Very roughly, 4,000 spacecraft have been put into earth orbit, and approximately 200 interplanetary spacecraft have been launched. To date, all power systems have been static systems. This is due to the high reliability that has been demonstrated by the systems with no moving parts. Static systems are not without reliability issues, with interconnections, thermal effects, degradation, etc., 
however they have proven themselves to be highly reliable over the years.

RTGs based on unicouples have proven themselves to be extremely reliable over many missions and many years of use. It is likely that if there were no issues associated with the cost or environmental impact of plutonium, that the RTG would continue to be the power system of choice in the future. However, since these considerations do exist, there is a need for a fundamentally higher efficiency power system, thus the use of the Stirling Radioisotope Power System (SRPS). The SRPS will be the first use of a dynamic power system in space.

The power system design has not been developed even though the TDC has been baselined as the convertor for the system. Both Orbital Sciences Corporation (OSC) Germantown, MD, and Lockheed Martin Astronautics (LMA) Valley Forge, PA have completed system studies based on the TDC. OSC has analyzed systems with either two or four convertors ${ }^{8}$. One of the layouts proposed by OSC is shown in figure 2. LMA has also investigated the possible system layouts ${ }^{9}$ and has proposed the SRPS shown in figure 3. In both configurations shown, heat is transferred from the centrally located GPHS modules to the Stirling convertors. The heat is converted into electric power and the waste heat is rejected to space by the radiators.

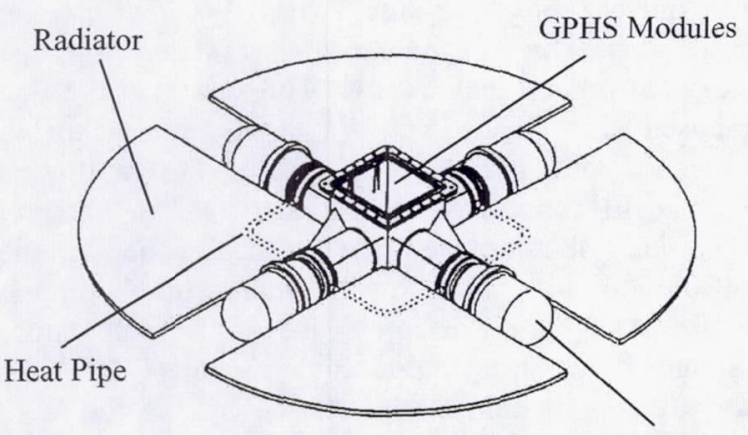

Stirling Convertors

Figure 2. Orbital Sciences Corporation System Concept.

\section{CRITICAL AREAS}

As mentioned earlier, Stirling power systems have touted the "potential for" a number of attractive attributes over the many years of development. The features that a free-piston Stirling power convertor could potentially achieve for space applications were high conversion efficiency, relatively low specific mass, coupled with long life and high reliability. Since the initial development of the free-piston Stirling convertors, which started in the 1960 's, the areas where there was a potential have one-by-one been achieved. The TDC development effort being conducted at STC for DOE was able to achieve the goals of power and efficiency in a relatively short time. Considering the intended application of the TDC, achieving long life and reliability is also essential.

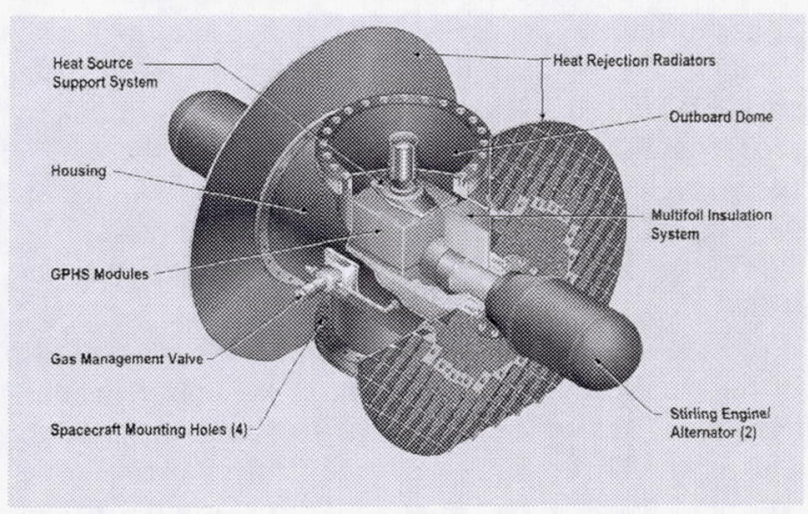

Figure 3. Lockheed Martin Astronautics System Concept.

In 1999, a joint government/industry team was assembled to evaluate the feasibility of using a flight version of the TDC in an SRPS for the Europa Orbiter and Solar Probe missions. The team included members from DOE, GRC, and JPL representing the government, along with LMA, STC, and Orbital Sciences. During this evaluation, there were three critical areas believed to be key to achieving long life. These areas were the heater head, the flexures, and the linear alternator magnets.

\section{Heater Head}

The issue with the TDC heater head was creep of the head over the life of the missions. Creep becomes a factor in the design since the heater head is highly stressed by the mean pressure of the Stirling cycle and operated at high temperature. Over time, the head will grow in dimension as a function of the level of stress, the temperature and material properties. This phenomenon exists in most all Stirling power converting machines whether they are free-piston or kinematic machines. Typically, a $1 \%$ creep criteria is used for the design of a Stirling heater head. The basis for this number has nothing to do with the impact on thermodynamic performance of the cycle nor the structural integrity of the heater head. An initial look at the performance of the TDC with $1 \%$ creep was performed at NASA GRC. This analysis should be viewed as preliminary and used to bracket the effect of creep on the TDC. If the head were allowed to creep the full $1 \%$, it appears that the power output may 
potentially be reduced by a few percent with constant heat input. This study is preliminary and the analysis needs to be refined.

In the case of the TDC, the heater head is fabricated from Inconel 718. Because of the extensive use of Inconel 718 in the aerospace industry, long term creep data can be found in the literature. Several points must be taken into account when considering the impact of creep in the case of the TDC. Based on the data available in MIL-HDBK-5G, November 1, 1994, a proper application of Inco 718 operated at the $650^{\circ} \mathrm{C}$ design temperature and stressed at $40 \mathrm{ksi}$ will creep $0.5 \%$ in $10^{5}$ hours (11.4 yrs). The design stress of the TDC is $16 \mathrm{ksi}$, providing a $150 \%$ margin of safety for $0.5 \%$ creep.

In this application, the heater head is subject to long term stress at temperature which results in pure creep. This is similar to the design requirements used during the SP-100 program where the free-piston Stirling convertor heater head was operated at a steady state condition with high temperature and stress from the Stirling cycle mean pressure ${ }^{10}$. Detailed analysis and material characterization led to a design projected to meet the 60,000 hour ( $6.8 \mathrm{yr}$ ) life requirement.

A much more challenging application of a Stirling convertor heater head was in the Advanced Stirling Conversion System (ASCS) project. Project requirements called for 60,000 hour life, however this had daily start-stop transients due to daily sun-up and sun-down ${ }^{11}$. In addition to the known daily excursions, it was estimated that the typical solar variations caused by passing clouds could cause as much structural damage to the heater head as the daily sun-up/sun-down events. Thus the heater head would sustain the equivalent of two full sun-up/sun-down thermal cycles per day. The $25 \mathrm{kWe}$ convertors were never operated to demonstrate long life, however detailed analytical techniques and material characterization indicated that the long life goals were able to be achieved.

\section{Bearing System}

Long life has been demonstrated in multiple free-piston Stirling convertors and has been a design goal in other projects where the hardware was designed but never fabricated. A common feature in each of the designs was the use of non-contacting moving parts, i.e. the pistons reciprocate axially in the cylinders but have no contact with the cylinder. Over the years a variety of methods have been used to achieve non-contacting operation.
Some of the early long life Stirling machines were developed by E. H. Cooke-Yarborough ${ }^{12,13}$. These convertors were intended for remote power generation applications requiring power levels typically less than 100-We. The Thermomechanical Generators (TMG) achieved long life through the use of flexing diaphragms to support the moving components. The longest demonstration of a TMG was with unit D2, which was taken out of operation in May, 1987, after operating for approximately 110,000 hours (12.6 yrs), which equates to approximately $3.3 \times 10^{10}$ cycles.

As part of the Thermal Ventricular Assist System (TVAS), the STC staff developed multiple generations of free-piston Stirling convertors. These devices were intended for being implanted in humans needing heart assist. They operated typically in the 3 to 5 watt range per the requirement of the application. System 4 operated for a total of 60,000 hours in the early 1970 s, with one continuous run of 36,000 hours $^{12}$. Other systems operated in the 10,000 to 20,000 hour range. The systems were a combination of pneumatic and hydraulic and made use of welded metal bellows to achieve long life.

During the mid 1980s and early 1990s free-piston Stirling development was concentrated more on the 10 to $30 \mathrm{~kW}$ range. This was for either SP-100 applications or for the DOE funded NASA managed ASCS project. The SP-100 system was intended to be a space nuclear power system with $100 \mathrm{~kW}$ electric power output. Free-piston Stirling was selected as the backup conversion technology. The system was to be composed of five $25 \mathrm{kWe}$ free-piston Stirling convertors, each operating at $80 \%$ of design power. Mechanical Technology Incorporated (MTI), Latham, NY, initially demonstrated performance needed for the SP-100 with the Space Power Demonstrator Engine (SPDE). MTI later designed the high temperature Component Technology Power Convertor (CTPC) for the SP-100 application ${ }^{10}$, which is shown in figure 4.

The ASCS project was intended to produce a commercially viable distributed dish solar terrestrial system to provide electric power for the domestic utility grid $^{11}$. A $25 \mathrm{kWe}$ ASCS design was produced by Cummins Power Generation (CPG), Columbus, IN. Both the MTI design for SP-100, and the CPG design for solar terrestrial applications used fluid film or gas bearings to achieve non-contacting operation. In the case of the MTI designs for SP-100 the gas bearings were hydrostatic. Through a system of ports, some of the peaks of the gas pressure waves were clipped and fed into an internal plenum that was charged to a pressure higher than the mean operating pressure. This plenum fed a series of small ports in the cylinder wall 
to provide the gas film to support the piston, and thus non-contacting operation was achieved. A similar arrangement was used on the displacer. This gas bearing system was successfully demonstrated in hardware and achieved non-contacting operation. The CPG design used hydrodynamic gas bearings. This was accomplished using a small electric motor to spin the piston and displacer. Care was taken during the design process such that the close clearances were able to act not only seals, but also as non-contacting hydrodynamic gas bearings. Although this was never demonstrated on the $25 \mathrm{kWe}$ ASCS design, the concept had been successfully demonstrated at Sunpower, Athens, $\mathrm{OH}^{11}$.

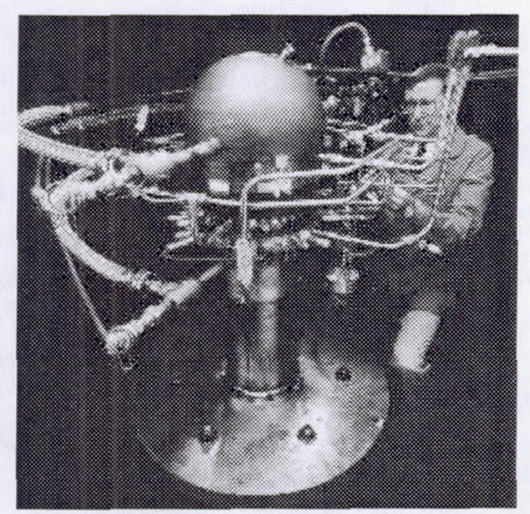

Figure 4. CTPC Being Readied for Test at MTI.

More recently, flexures have been used on long life machines. One of the finest examples of this is the Radioisotope Stirling Generator (RSG) designed and build by STC ${ }^{14,15}$. The RSG is shown in figure 5 . The STC flexures, which originated in the heart program appear to be particularly attractive at power levels up to hundreds of watts, and extend into the low $\mathrm{kW}$ range. The flexures are relatively stiff in the radial direction and have a predetermined stiffness in the axial direction. This allows the piston to move in the axial direction with relatively little motion in the radial direction. The axial stiffness acts as part of the spring that determines the frequency at which the system operates. Since there can be a well defined linear motion with the proper application of flexures, a piston can oscillate axially in a cylinder and maintain close clearance between the piston and cylinder without contact.

This has been demonstrated on the RSG which has accumulated over 60,000 hours of continuous operation without degradation. Other examples of flexure machines are the STC 55 We TDC which recently operated at full power conditions while being subject to over $12 \mathrm{Grms}$ random vibration for three minutes in each axis. The test set up is shown in figure 6 .
Following the vibration test the TDC was operated for another 35 hours ( $10^{7}$ engine cycles) with no change in performance, and then disassembled and inspected. No effects of the vibration testing were found upon inspection ${ }^{9}$.

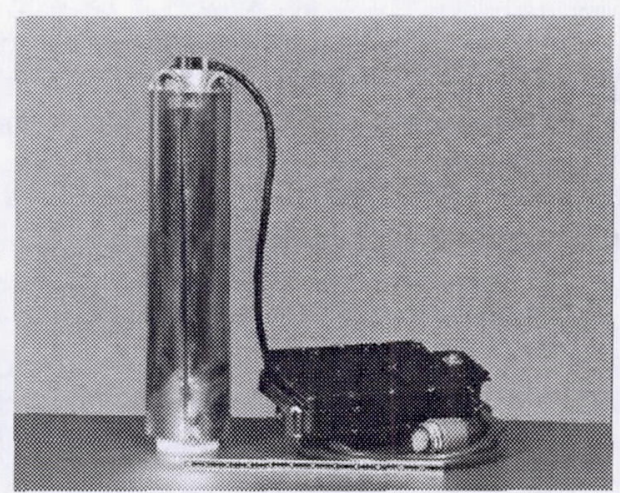

Figure 5. The $10 \mathrm{We}$ RSG by STC has Over 60,000 Hours of Operation.

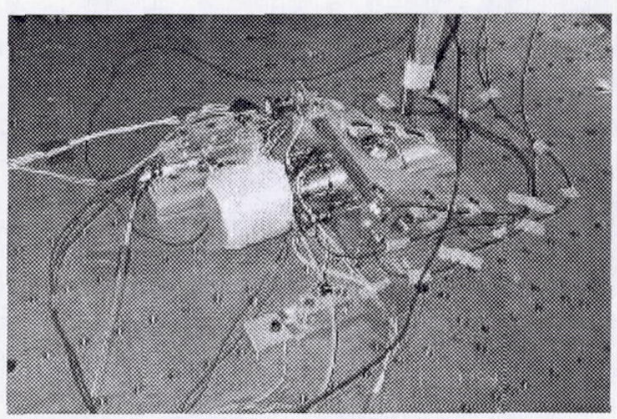

Figure 6. The TDC Installed for Random Vibration Test Conducted at GRC.

Similar applications of flexure bearing technology can be found in the aerospace Stirling cycle cryocoolers ${ }^{12}$. Long life operation of these flexure based cryocoolers has also been demonstrated with multiple demonstrations into the 20,000 and 30,000 hour range $\mathrm{i}^{12,16,17,18}$. There are several issues involved in obtaining long life with the application of flexures. One is to clearly understand the state of stress in the flexure, the fatigue limits of the material, and thus the margin of safety. Beyond this, there are details in the design, fabrication, inspection, and installation of flexures that are critical. These factors may be addressed somewhat differently by each company based on their specific experiences. The common finding by the various users of flexure technology for linear oscillating machines is that when designed, fabricated, and installed correctly, they are capable of providing essentially infinite life. 


\section{$\underline{\text { Linear Alternator Magnets }}$}

Within the free-piston Stirling power convertor is a linear alternator used to convert the linear motion of the free-piston Stirling engine into electricity. Most high performance linear alternators used today have permanent magnets, either stationary or moving with the power piston. The linear alternator is one of the more difficult areas to analyze in the free-piston Stirling convertor, and more specifically the stress on the magnets is very difficult to analyze. As is the case with the application of flexures, the key to long life is adequate margin in the design. The margin is the difference between the magnetic stress experienced relative to the condition at which the magnets start to become demagnetized. When the aforementioned joint team was evaluating the technology readiness of the TDC for the space power application, one of the key issues was the temperature margin of the magnets.

Analysis was performed to determine the operating temperature of the magnets. These are embedded in the linear alternator, which is enclosed in the pressure vessel that has a partial view of space. Based on some of the thermal analysis that was used to evaluate the Cassini power system, and extending it to model the SRPS, it was found that the magnets would operate around $70^{\circ} \mathrm{C}$. Since the data for the candidate magnets indicated that they should be able to operate with long life at temperatures up to approximately $140^{\circ} \mathrm{C}$, there appears to be about $70^{\circ} \mathrm{C}$ margin. This margin, coupled with laboratory tests to characterize the candidate magnets was used to ensure long life.

Magnets for Stirling convertors have been characterized in the past at $\mathrm{GRC}^{19,20,21}$ however these were high temperature Samarium-Cobalt $(\mathrm{SmCo})$ magnets. An effort is currently underway to characterize some of the more advanced Iron-Neodymium-Boron (FeNdB) magnets ${ }^{22}$. Long life data for magnets available in the open literature typically ends at 10,000 hours because the magnet industry believes that there is little if any aging that occurs after the initial operation.

\section{OTHER AREAS OF CONCERN}

Hermeticity - The outer surface of the free-piston Stirling power convertor is a pressure vessel. To achieve the long life needed for space power applications, the pressure vessel must contain the inventory of helium working fluid. Major joints exist in the pressure vessel as the operational components of the Stirling machine are enclosed by the pressure vessel. High quality brazes and welds are essential in these areas. There are penetrations through the pressure vessel to carry the output form the linear alternator. A pinch tube is typically used to fill the convertor with the working fluid and is then pinched and sealed to hold the working fluid. Initial calculations indicate that if a Stirling convertor were to leak at rates up to those able to be detected by laboratory equipment, that the convertor performance would change little over the mission lifetimes being considered. The ability to hermetically contain the helium working fluid has been demonstrated and is therefore not a technology issue.

Controller - The free-piston Stirling convertor needs a controller to manage the power output. Generally, the controller accepts the ac power output from the linear alternator, tunes the output to correct the power factor, rectifies the ac to dc, and then if needed it will manage the power output that is not used by the end user. Past experience with spacecraft indicates that the electronics is an area with challenges in obtaining long life and reliability. This is among the reasons why the controller for a flight system should be kept as simple as possible. Controllers have been successfully developed for Stirling cryocoolers for application in space, and the controller for a Stirling power convertor is considered to be more simple than a controller for a Stirling cryocooler. The controller for the cooler converts dc power into an ac wave form to drive the compressor, and must do so at a required drive voltage. If the displacer is driven, a second ac wave must be generated with the required amplitude and phase angle relative to the compressor drive signal. This is sometimes done based on input to the controller from sensors on the cooler, which add another level of complexity. If dynamic balancers are used, additional signals must be sensed and drive signals generated with the required amplitudes and phase angles.

Fasteners - Past Failure Modes and Effects Analyses (FMEA) have identified fasteners as an area of concern for long life and reliability. While it would be desirable to eliminate any unnecessary fasteners, there does not appear to be a clear way to do this. Since it is inevitable that fasteners will be used, accepted high quality aerospace practices can be applied to assure long life and reliability.

Out-gassing \& Condensation - Contamination in Stirling cryocoolers has proven to be a challenging issue in pursuit of long life and reliability. Some of the materials used in the assembly out-gas over long periods of time. These materials tend to be the organics that have been used as adhesives, bumpers, wear surfaces, and thermal barriers. The coldest surface in a Stirling cryocooler that the working fluid comes into contact with is in the expansion space, inside the cold finger. This surface is part of a critical heat exchanger, 
and is located adjacent to the regenerator, which can also be considered to be a critical heat exchanger. Contaminants to the working fluid that were outgassed from the organics will be deposited on the cold surface and degrade the performance of the cryocooler. One method used to counteract this effect is to design the cryocooler to operate at a derated condition (shortened compressor stroke) at the beginning of life, and then transition the operation to full rated operation (full piston stroke) as time progresses. Deposits and fouling of heat exchangers is one of the reasons why achieving long life and reliability in a Stirling cryocooler is very challenging.

In a free-piston Stirling power convertor, and more specifically in the space application, the coldest surface to which the working fluid is exposed is the interior surface of the pressure vessel that encloses the linear alternator. This large surface is not used as a heat exchanger for the thermodynamic cycle. From the thermal perspective, it serves only to reject a small amount of waste heat from the linear alternator and therefore is relatively insensitive to any contaminants that may deposit.

\section{EXAMPLES OF LONG LIFE}

Stirling cycle machines date back to 1816 at which time they were large devices operating on one atmosphere of air as the working fluid. More modern Stirling machines, either coolers or power convertors, use superior working fluids such as helium or hydrogen, and operate with the mean cycle pressure above one atmosphere. Machines with these working fluids have been in existence for approximately 60 years. The freepiston Stirling, used as either a cooler or a power convertor has been in existence for slightly over 30 years. Much of the initial development centered on general issues, examples of which were the overall configuration-design-fabrication, understanding the interrelationship between dynamics and thermodynamics, development of the power output conversion technologies (linear alternators, pumps, compressors), control strategies, etc. During this time it was rare to have a long term project that would present an opportunity to demonstrate long life. Stirling machines exist that have demonstrated long life, and there are other Stirling machines that have been operated and are believed to be capable of long life but were never used to demonstrate this capability.

As mentioned earlier, the TMG was able to demonstrate long life through the use of diaphragms to control the movement of the oscillating parts. It achieved 110,000 hours of operation before being deactivated. The TVAS System 4 heart assist Stirling operated a total of
60,000 hours with one continuous run of 36,000 hours. The RSG is based on flexure technology and has nearly 60,000 hours of continuous operation with no measurable degradation in power output nor efficiency. The TDC is based on the same technologies as the RSG and was able to successfully demonstrated $10^{7}$ cycles of operation following a series of random vibration tests far in excess of the vibration expected at launch.

There are also examples of long life demonstrated in Stirling cryocoolers. As is the case with cryocoolers developed by TRW, British Aerospace, Ball Aerospace and others, these are based on flexure technology to achieve non-contacting operation. Data points up to 32,000 hours (3.7 yrs) have been published ${ }^{18}$. The Stirling cryocooler industry has accepted a practice that if a cooler demonstrates approximately 1 year of operation it is considered to have long life capability. This is based on experience that failures will be evident in less than 1 year. Failures beyond this point in operation are purely random and not attributable to design nor fabrication.

The SPDE \& CTPC had proven the capability of noncontacting during operation in the test cells. Based on material characterization and detailed structural analysis of the highly stressed components, they were believed to be fully capable of long life, however, for programmatic reasons a long life demonstration for these convertors was never funded.

\section{CONCLUSIONS}

Free-piston Stirling machines for power conversion and for cooling have been under development for slightly more than 30 years. Even though some machines were designed with the capability for long life, during this time period there have been limited opportunities to demonstrate long life. Looking at the examples where long life has been demonstrated there are some common themes that have led to the success. First, systems have often been used to provide non-contacting operation of the moving parts. Between the power applications and cooling applications there are numerous examples of this. Secondly, there has been a firm appreciation of the time dependant aging processes and sufficient margins were applied to the design. This is evident in the heater heads that creep as a function of stress level, time and temperature. This is also evident in the application of flexures or diaphragms when they are used to achieve non-contacting operation, and in the permanent magnets of the linear alternators when the output of the convertor is electric power.

It is believed that obtaining the long life in a free-piston Stirling convertor does not require new, advanced 
technologies, rather it can be attained through sound engineering in the application of existing technologies. As evidenced by the data, the technologies needed for long life Stirling machines exists today and the issues that must be addressed are design and application specific.

\section{REFERENCES}

[1] Space Satellite Handbook, Third Edition, Anthony R. Curtis, Editor, Copyright 1994, Gulf Publishing Company.

[2] Space Exploration: Power Sources for deep Space Probes, GAO NSIAD-98-102, 1998.

[3] Mondt, J.F.; Underwood, M.; and Nesmith, B.: Future Radioisotope Power Needs for the Missions to the Solar System, Proceedings of the $32^{\text {nd }}$ Intersociety Energy Conversion Engineering Conference, 1997.

[4] Mondt, J.F.; and Nesmith, B.J.: Future Planetary Missions Potentially Requiring Radioisotope Power Systems, Proceedings of the Space Technology and Applications International Forum, 2000.

[5] Frazier, T.: Advanced Conversion Technology Review Panel Report, Proceedings of the $33^{\text {rd }}$ Intersociety Energy Conversion Engineering Conference, Paper IECEC-98-398, 1998.

[6] White, M.A.; Qiu,S.; Erbeznik, R.M.; and Welty, S.C.: Status of an Advanced Radioisotope Space Power System Using Free-Piston Stirling Technology, Proceedings of the $33^{\text {rd }}$ Intersociety Energy Conversion Engineering Conference, Paper IECEC-98-417, 1998

[7] White, M.A.; Qiu, S.; Olan, R.W.; and Erbeznik, R.M.: Technology Demonstration of a Free-Piston Stirling Advanced Radioisotope Space Power System, Proceedings of the Space Technology and Applications International Forum, 1999.

[8] Schock, A.; Or, Chuen; and Kumar, V: Radioisotope Power System Based on Improved Derivative of Existing Stirling Engine and Alternator, Proceedings of the Space Technology and Applications International Forum, 1999.
[9] Evaluation of Stirling Engine Technology, Lockheed Martin Astronautics, Topical Report LMSP-7268, Prepared for the Department of Energy, Contract Number DE-AC03-98SF21256, 2000.

[10] Dahr, M.: Stirling Space Engine Program, NASA CR-1999-209164, 1999.

[11] Shaltens, R.K.; Schreiber, J.G.: Update on the Advanced Stirling Conversion System Project for $25 \mathrm{~kW}$ Dish Stirling Applications, Proceedings of the $27^{\text {th }}$ Intersociety Energy Conversion Engineering Conference, 1992.

[12] Ross, B.A.; and Dudenhoefer, J.E.: Stirling Machine Operating Experience, Proceedings of the $26^{\text {th }}$ Intersociety Energy Conversion Engineering Conference, 1991, NASA TM104487, 1991.

[13] McBride, J.R.,; and Cooke-Yarborough, E.H.: The Homach TMG: A New Stirling Power Source for Unattended Operation, Proceedings of the $19^{\text {th }}$ Intersociety Energy Conversion Engineering Conference, 1984.

[14] Erbeznik, R.M.; and White, M.A.: Test Results and Commercialization Plans for Long Life Stirling Generators, Proceedings of the $31^{\text {st }}$ Intersociety Energy Conversion Engineering Conference, 1996.

[15] Montgomery, W.L.; and Penswick, L.B.: Third Generation Development of an 11-Watt Stirling Converter, Proceedings of the $31^{\text {st }}$ Intersociety Energy Conversion Engineering Conference, 1996.

[16] Ross, R.G.: JPL Cryocooler Development and Test Program: A 10-year Overview, Proceedings of the Institute of Electrical and Electronics Engineers Aersopace Conference, 1999.

[17] Carrington, H; Gully, W.J.; Kiehl, W.K.; Banks, S.; James, E.; and Castles, S.: Functional and Life Test Data for a Two-Stage Stirling Cycle Mechanical Cryocooler for Space Applications, Proceedings of the Space Technology and Applications International Forum, 1998.

[18] Tward E.; and Davis, T.: High Efficiency Cryocooler, Presented at the American Institute of Aeronautics and Astronautics Space Technology Conference and Exposition, 1999. 